\title{
الحداثة وتمثيلاتها البصرية بالعمارة والتصميم
}

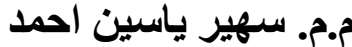 \\ كلية الفنون التطبيقية ـ الجامعة التقنية الوسطى ـ العراق \\ البريد الاكتتروني: Saahyassan@mtu.edu.iq
}

طبيعة الإنسان هي في كلّّ زمان ومكان اقتران جسم بوعي، هما وجهان للتعبير عن حقيقة واحدة، متميزان، لكنْ غير منفصلين. إن كـلاً من هذين الوجهين ينمو ويتطور ويتتوع تلقائيًا و عفويَّا، من الحياة حتى الممـات. لكن

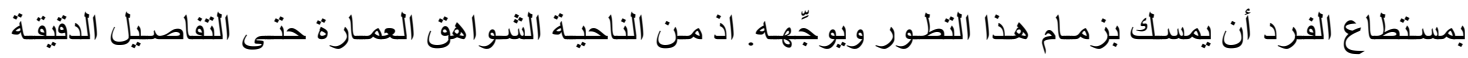

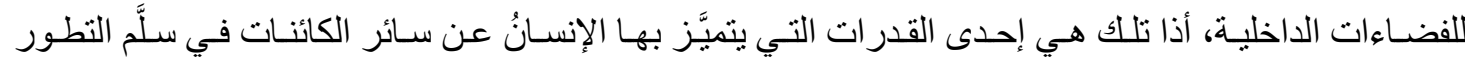
الأرضي. ويتفرع عن هذا الواقع نوعان من الثقافة، وُجدا في سائر البلدان وجميع العصور، لكنْ بوجود اختلافات

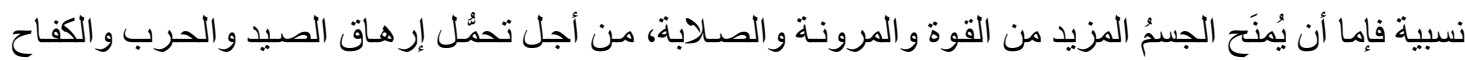
اليومي ضد قوى الطبيعة، و إما ان ييقى الجسم هو هدف الجهود الفرديـة الأوحد، لأن للوعي أيضًا متطلباتِهـ. إن أصل هذا التذوق وتللك الدو افع لبس في الجسم امنَّا، كما أنه يقينًا، ليس في البيئة المحيطة بنا، الأمر الذي يدعونا إلى ولوج في مستوى ثالث للوعي، نكون فيه شهودًا فاعلين، بأفكارنـا وبأعمالنـا، قادرين على اختيار مـا يتناسب منها مع تحقيق هذا الوعي هو مـاندعوه بـالوعي الروحي، الذي أسُّهـ تحرير الوعي من قيود الأنيَّة الثخصية

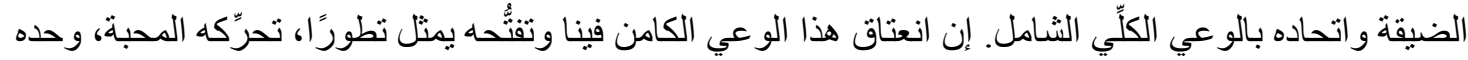

من شأنه أن يساعدنا على فهم المغزى من الحياة بعامة، و المغزى من حياتتا بخاصة. 


\begin{tabular}{|c|c|c|c|c|}
\hline 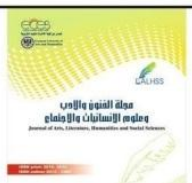 & \multicolumn{3}{|c|}{$\begin{array}{c}\text { هournal of Arts, Literature, Humanities and Social Sciences } \\
\text { www.jalhss.com }\end{array}$} & \\
\hline$=$ & Volume (74) & December 2021 & العدد (74) ديسمبر 2021 & \\
\hline
\end{tabular}

\title{
Modernity and its Visual Representations in Architecture and Design
}

\author{
Assist. Lect. Suhair Yassin Ahmed \\ College of Applied Arts - Central Technical University - Iraq \\ Email: saahyassan@mtu.edu.iq
}

\begin{abstract}
The nature of man is in every time and place the association of a body with consciousness, two aspects of the expression of one truth, distinct, but not separate. Both of these aspects grow, develop, and vary spontaneously, from life to death. But the individual can take control of this development and direct it. From the point of view of architecture, to the minute details of the interior spaces, then this is one of the capabilities that distinguishes man from other creatures in the ladder of earthly development. Two types of culture are branched from this reality, found in all countries and all ages, but with relative differences. Either the body is given more strength, flexibility and rigidity, in order to withstand the fatigue of hunting, war, and the daily struggle against the forces of nature, or the body remains the only goal of individual efforts. Because consciousness also has its requirements. The origin of this taste and those motives is not in the body, and it is certainly not in the environment around us, which calls us to enter into a third level of consciousness, in which we are active witnesses, with our thoughts and actions, able to choose what is commensurate with the realization of this awareness. What we call spiritual awareness, which is established by the liberation of consciousness from the constraints of the narrow personal ego and its union with the universal consciousness. The liberation and unfolding of this consciousness within us is a development, moved by love, that alone can help us understand the meaning of life in general, and the meaning of our life in particular.
\end{abstract}

Keywords: modernity, visual representations of modernity, architecture, design. 


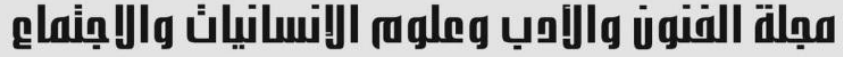

Journal of Arts, Literature, Humanities and Social Sciences www.jalhss.com

مثكلة البحث

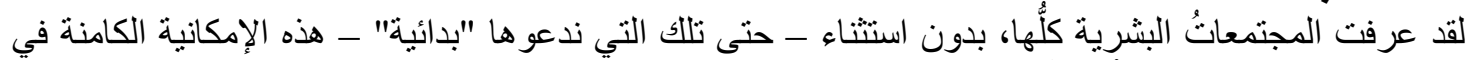

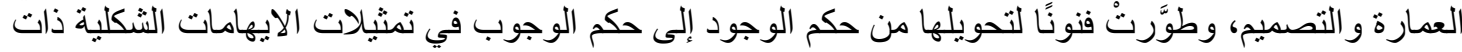

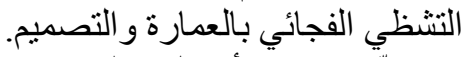

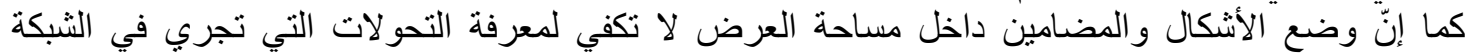

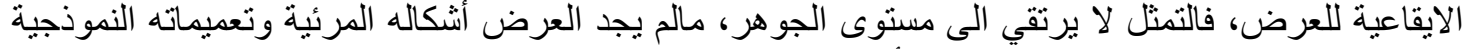

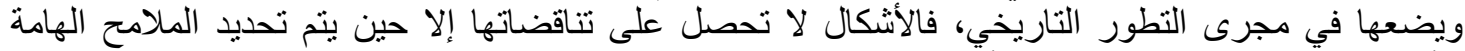
للأشياء و الظو اهر ومعرفة الطرق الأساسية و اتجاه تطور ها. فالتمثل الفكري هو الواقع الجديد الذي أدخلته الممارسة إلى إمكانية إنتاجية فجعلت منه اللحظة المفارقة للوعي،

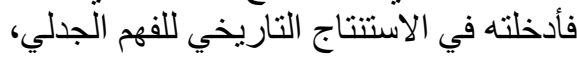

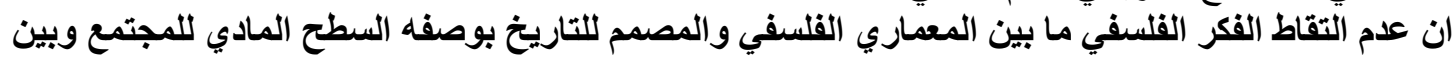

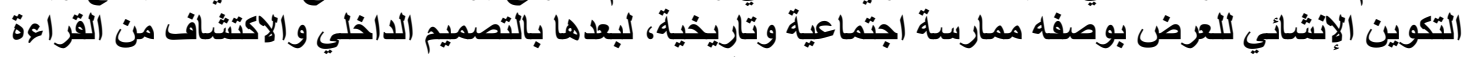

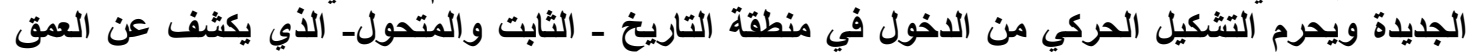
الجوهري للظاهرة.

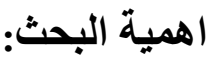
تتجلى الهمية البحث بالآتي :-

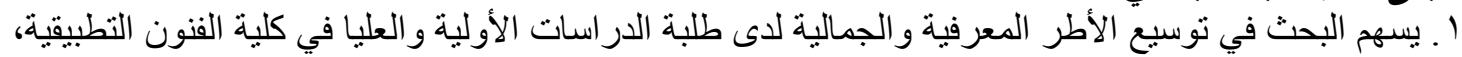

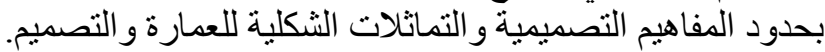

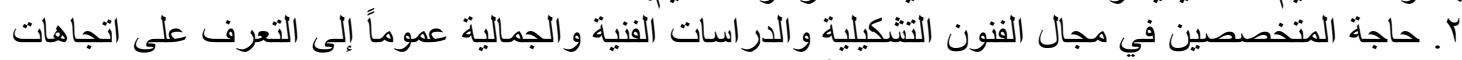

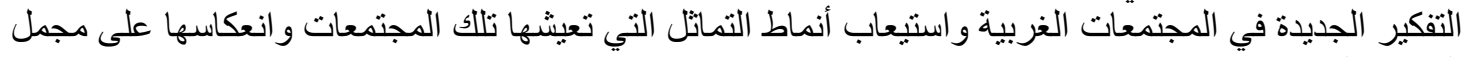
الثقافة و الفنون

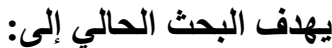

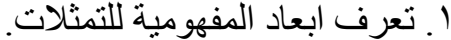
r. تعرف تمثلات الايهام البصري بالعمارة والتصميم في فن ما بعد الحداثة.

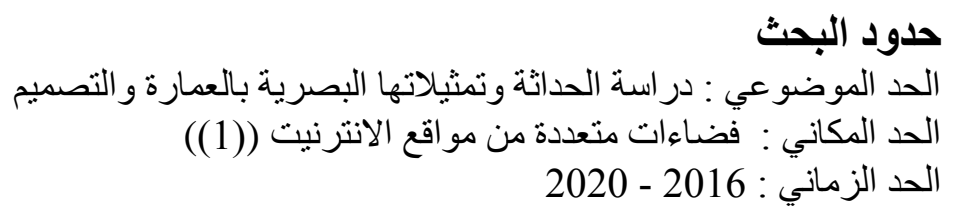

المصطات

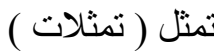

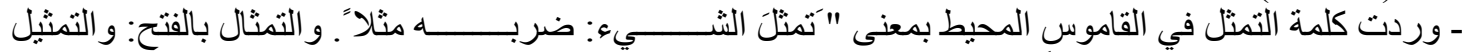

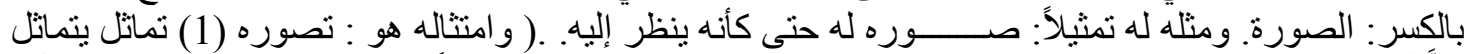

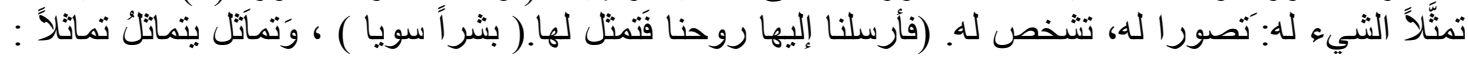

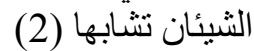

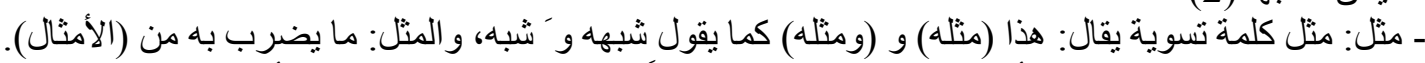

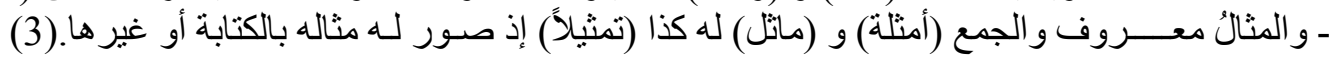




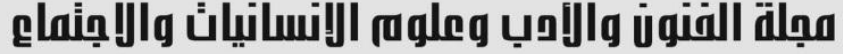

Journal of Arts, Literature, Humanities and Social Sciences www.jalhss.com

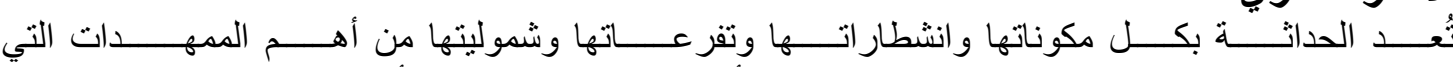

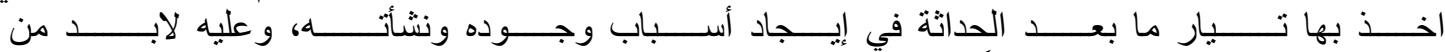

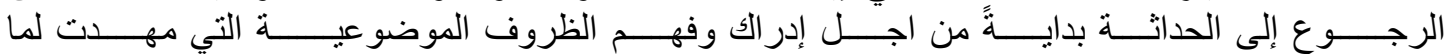

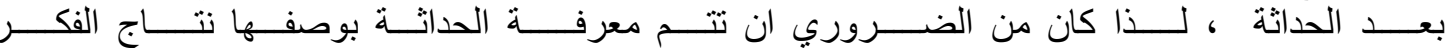

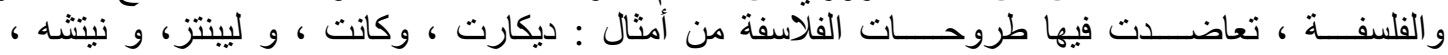

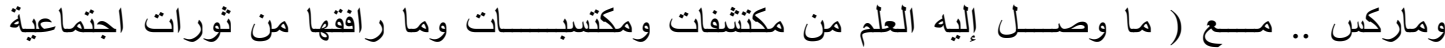

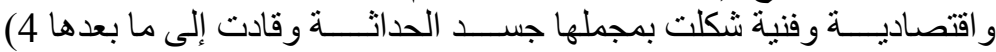

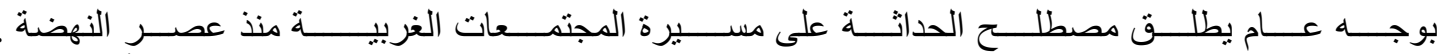

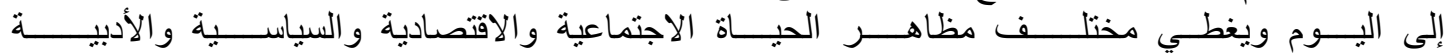

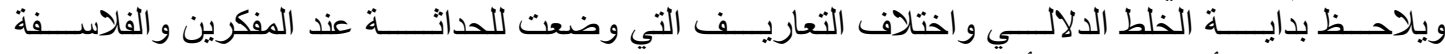

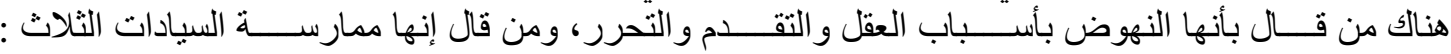

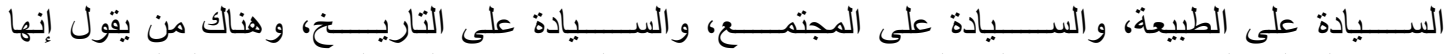

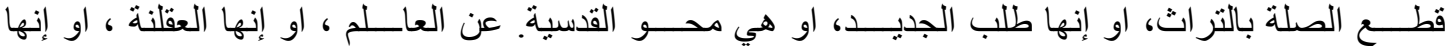

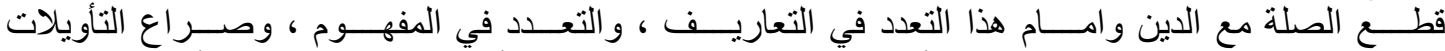

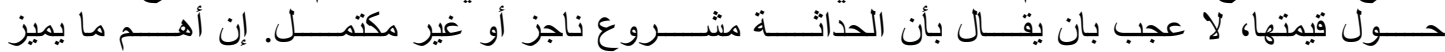

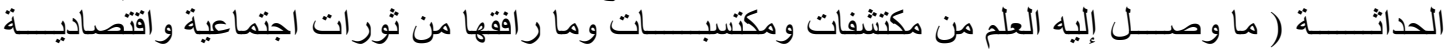

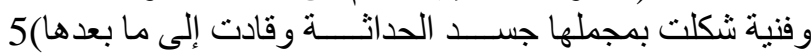

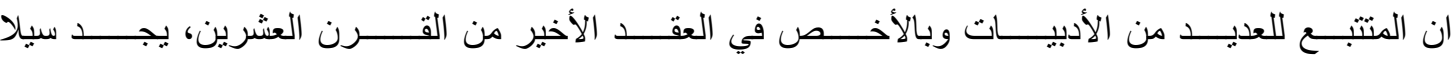

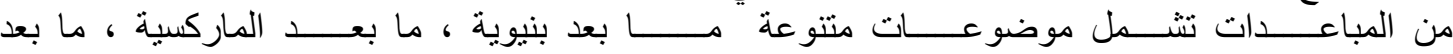

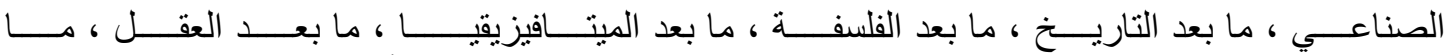

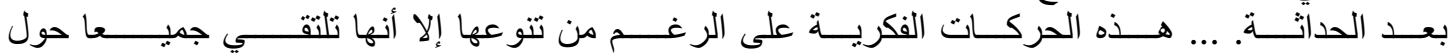

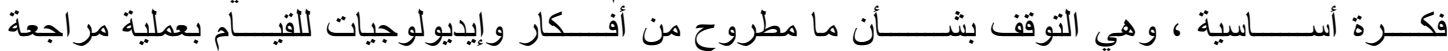

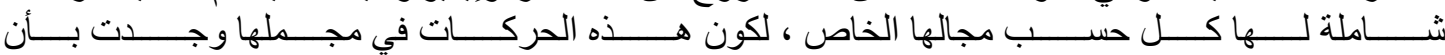

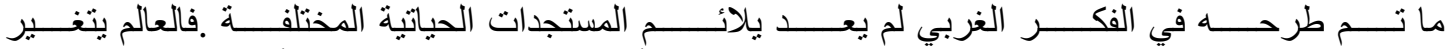

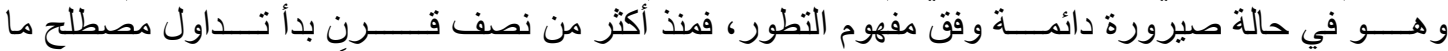

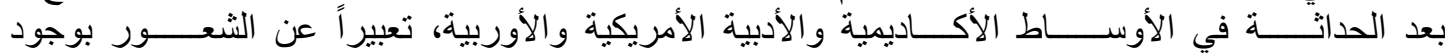

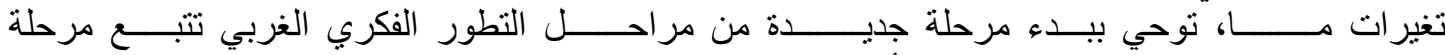

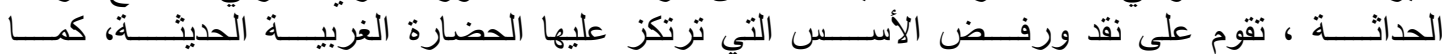

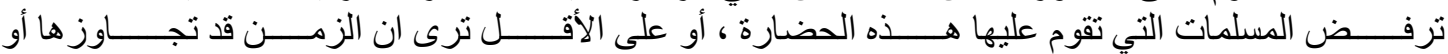

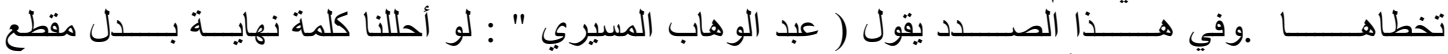

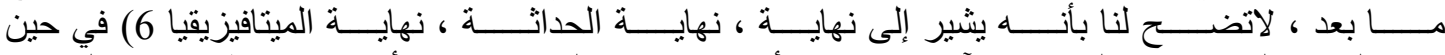

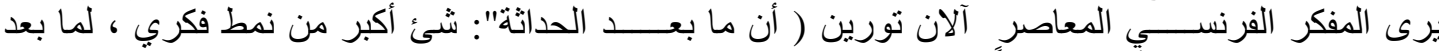

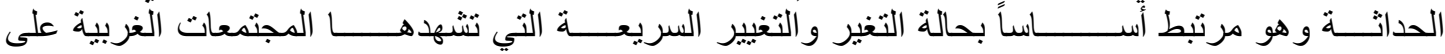

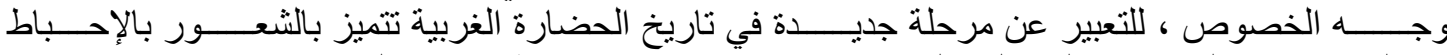

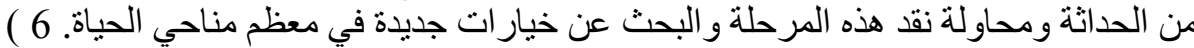

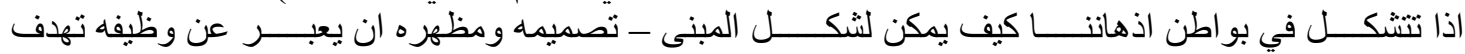

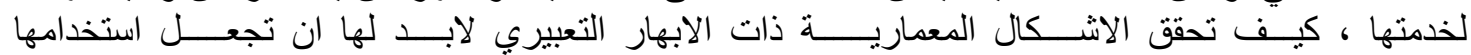

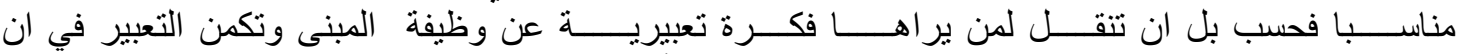

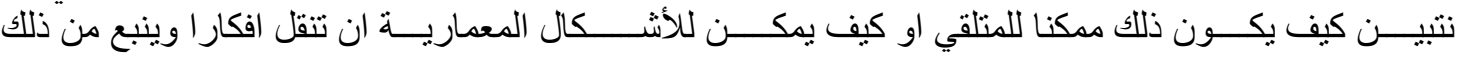

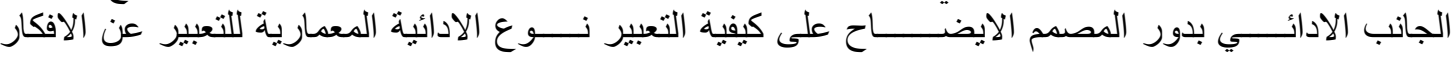
الوظيفية من النوع الذي لا يكون معبر ا عن نمط او طر ازيفي. 


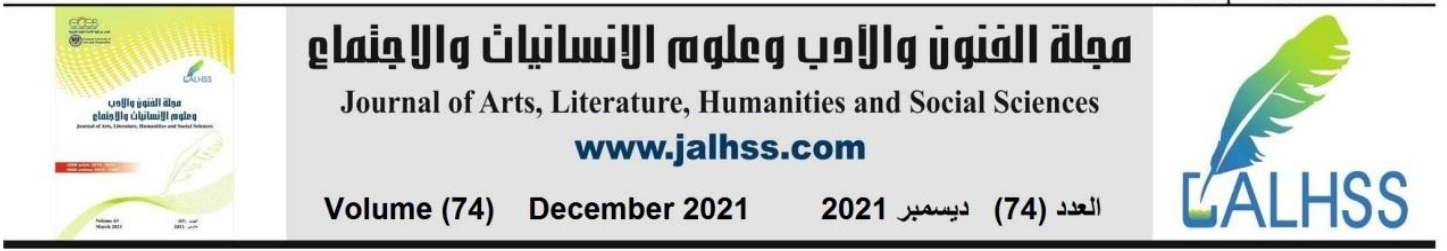

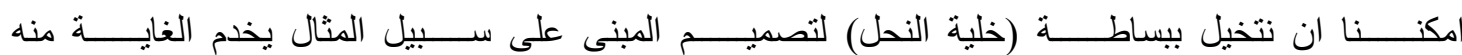

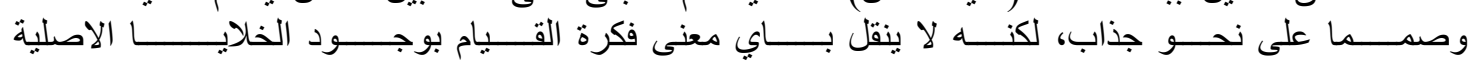
(النحــل كما في الشكل (1 - (1)

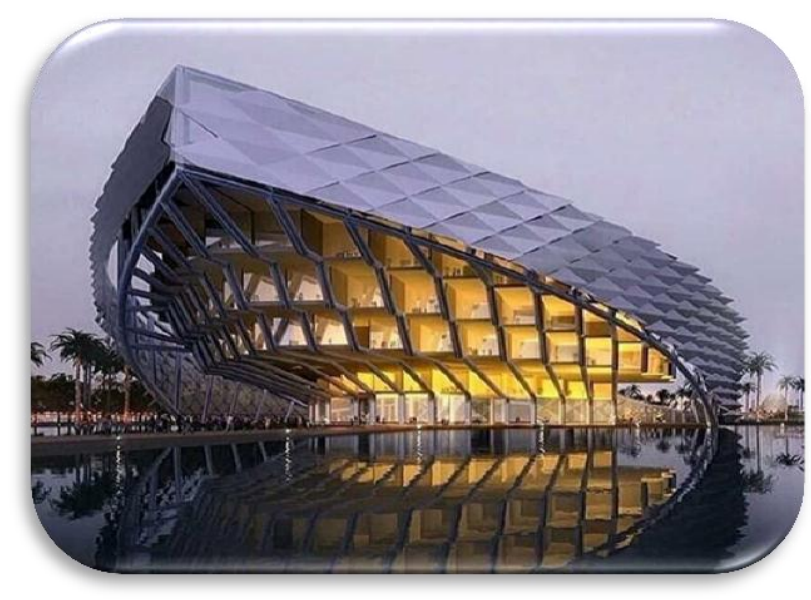

شكل رقم (1 - 1 ) الاشكال التعبيرية لخلية النحل المصدر الانترنت

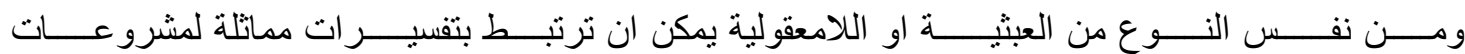

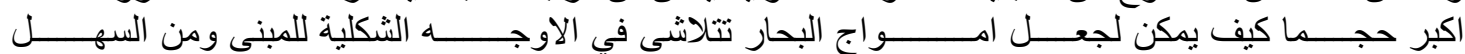

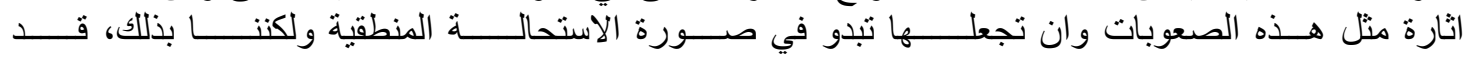

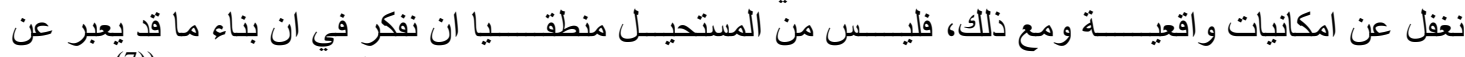
الفخامة او الاناقة (7) كما في في في

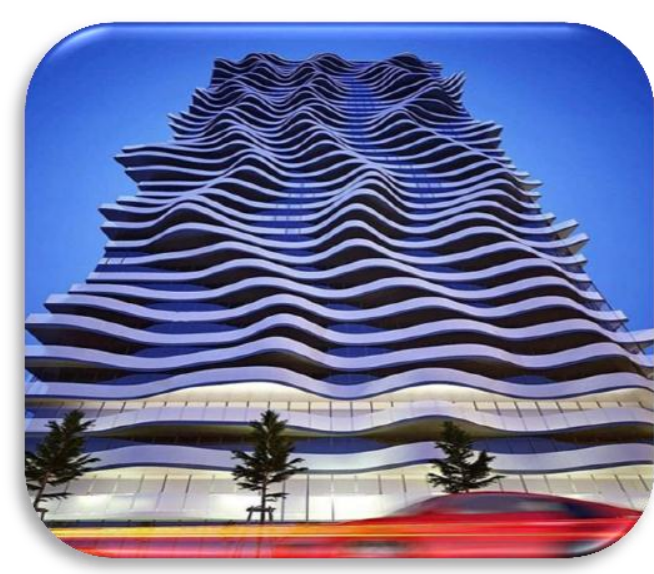
فكرة من نوع من المانيات فكرة

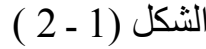

شكل رقم (1-2) الحركة الديناميكية المصدر الانترنت 


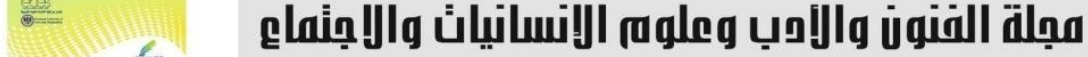

Journal of Arts, Literature, Humanities and Social Sciences www.jalhss.com

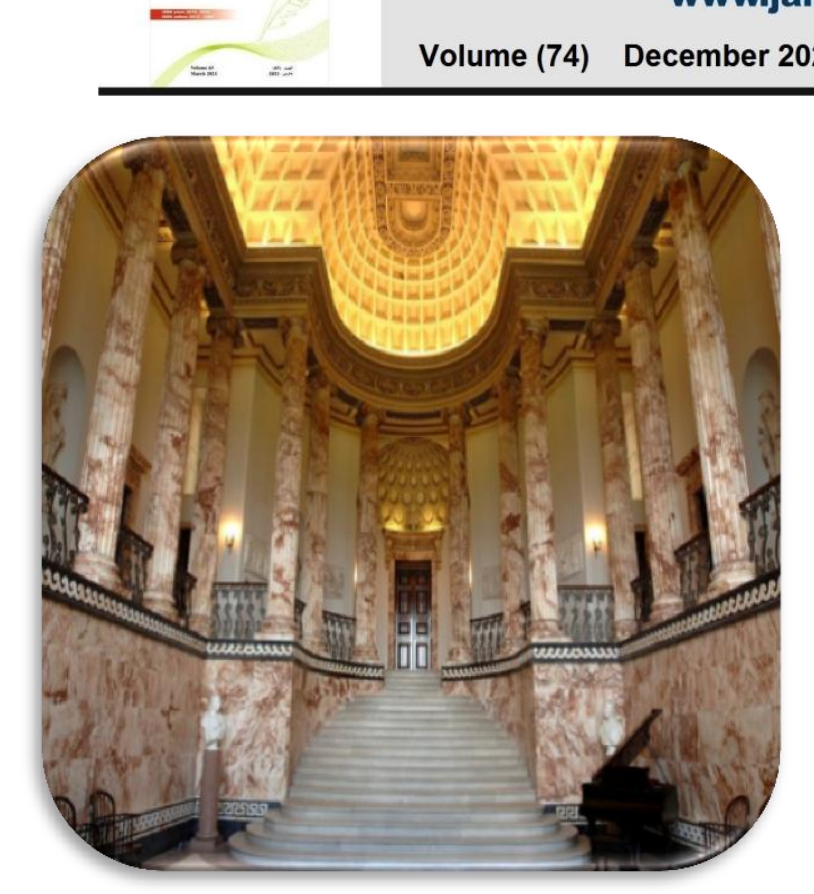

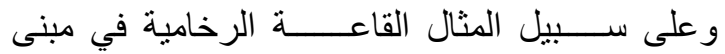

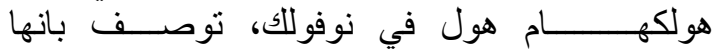

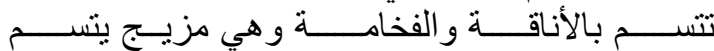

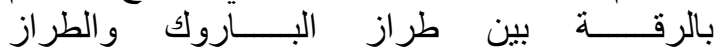

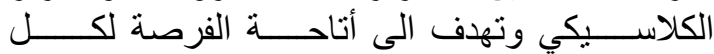

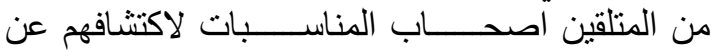

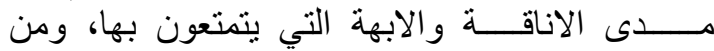

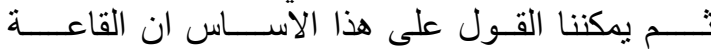

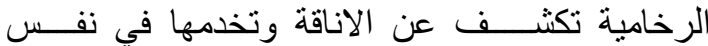
الوقت وبهـــــا الاطر اء فان شكلها يعبر عن وظيفتها

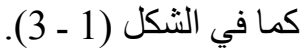
شكل رقم (1-3) القاعة الرخامية المصدر الانترنت

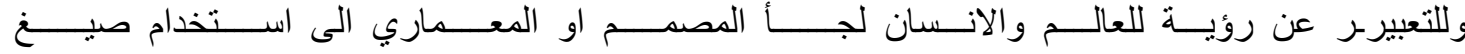

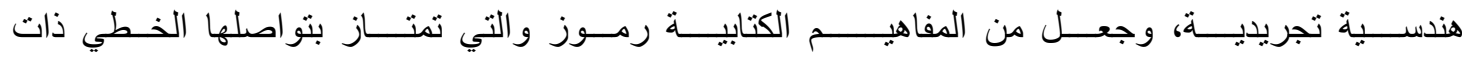

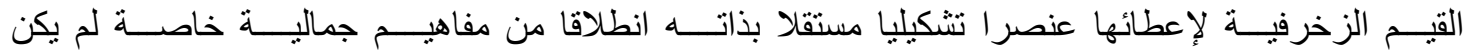

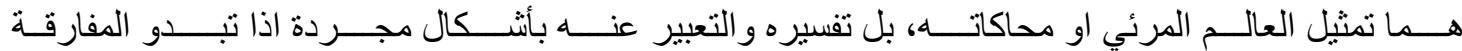

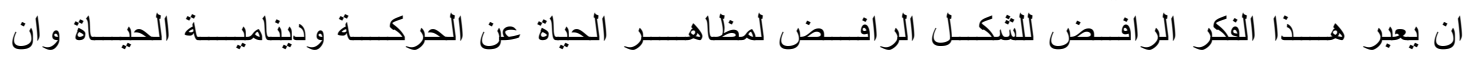

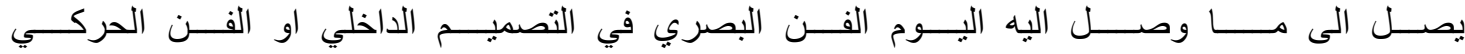

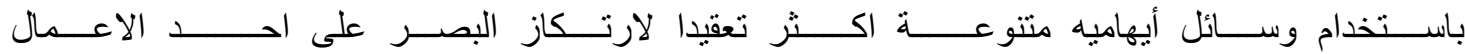

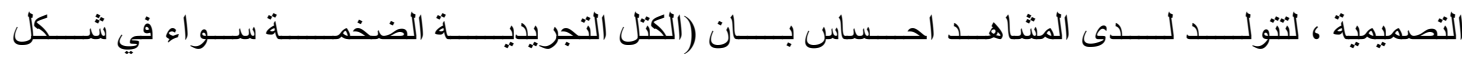

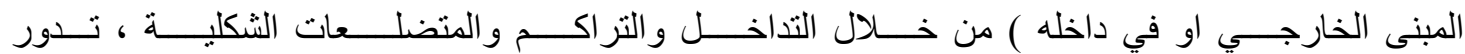

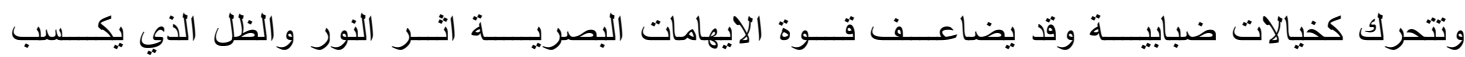

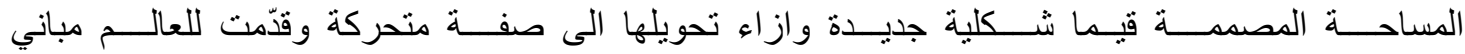

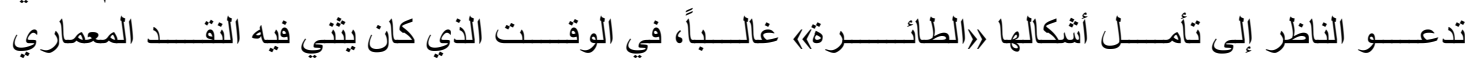

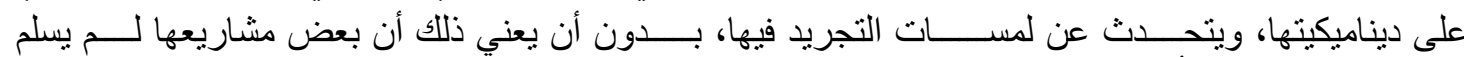

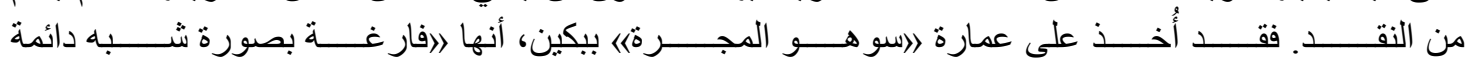

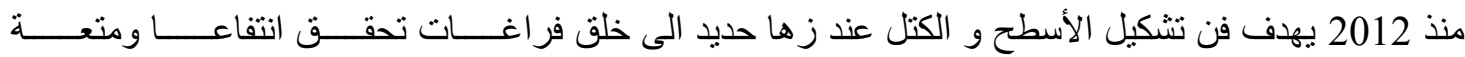

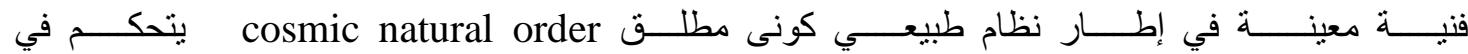

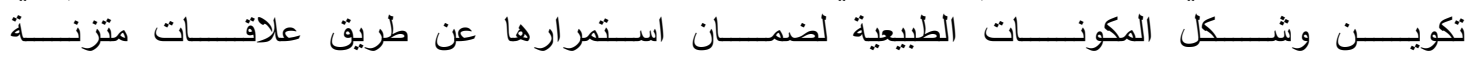

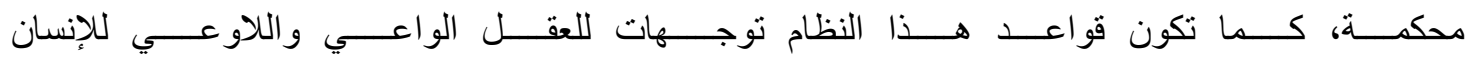

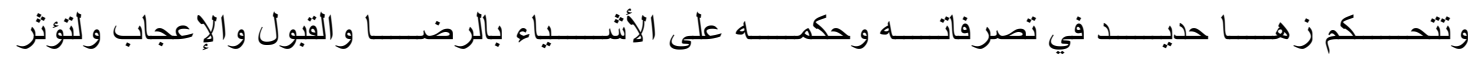
في تقديره لكل من الجمال أو الانبهار. 


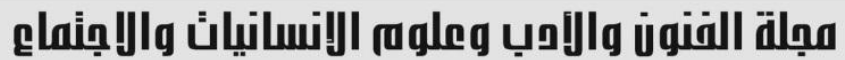

Journal of Arts, Literature, Humanities and Social Sciences www.jalhss.com

\section{Volume (74) December $2021 \quad$ العدد (74) يسمبر 2021}

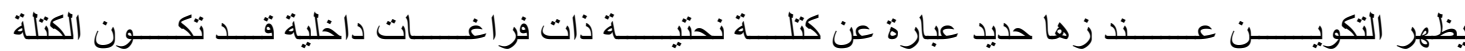

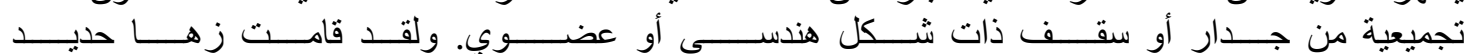

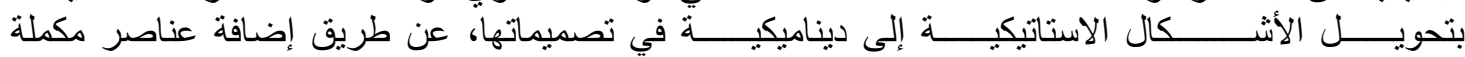

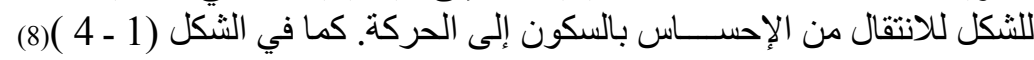

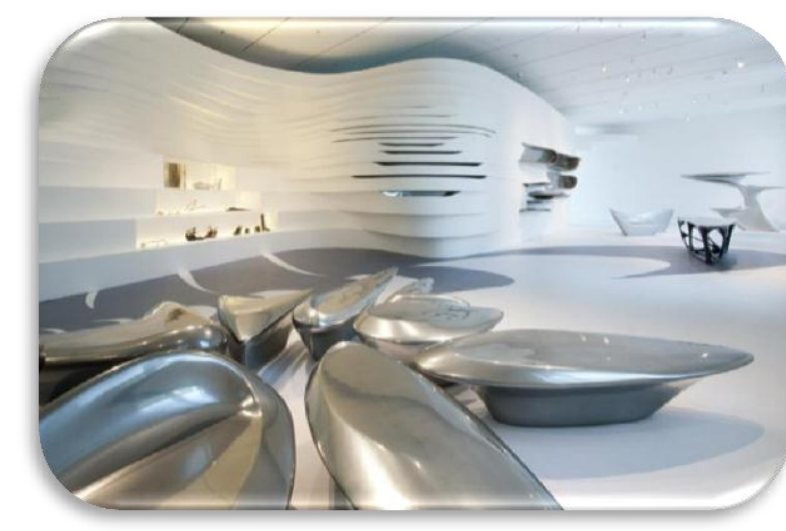

$$
\text { شكل رقم (1 -4 ) الحركة و السكون تصميم زهاء حديد }
$$

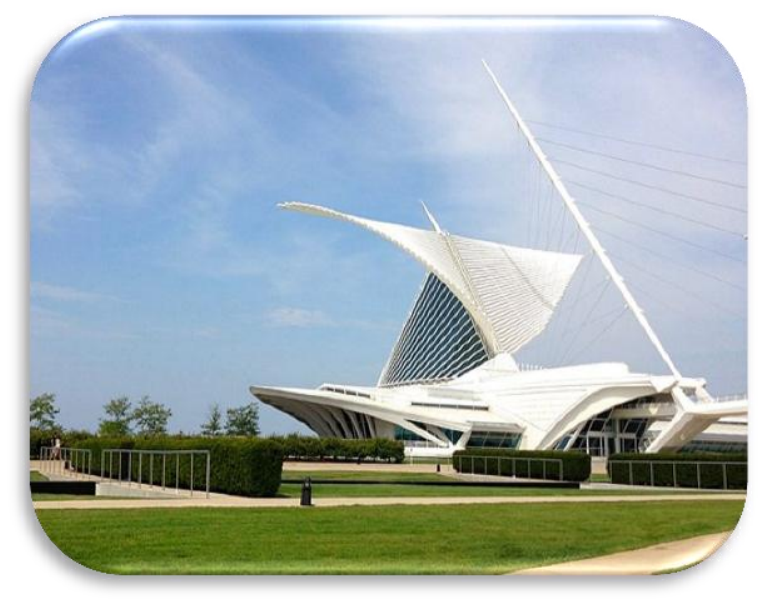

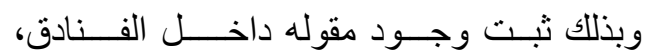

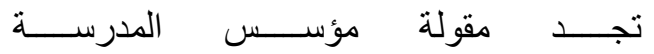

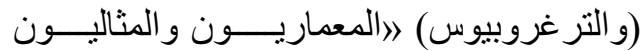

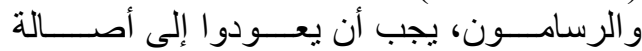

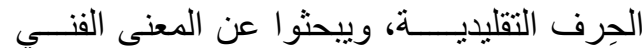

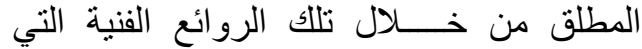

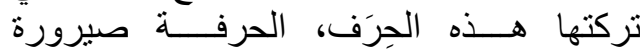

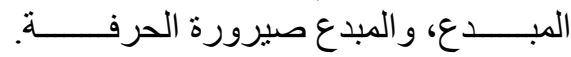

$$
\text { شكل رقم (1-5) الحركة متحف الفن المبلووكي }
$$

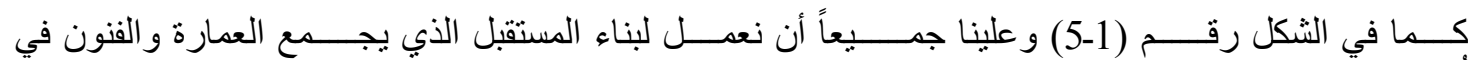

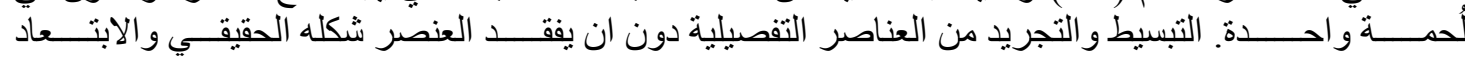

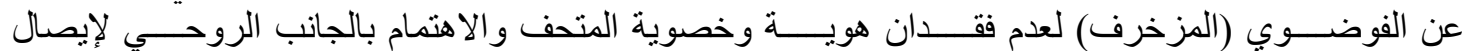

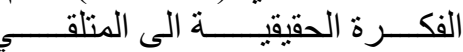




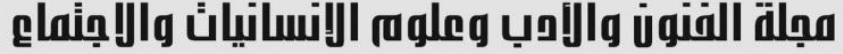

Journal of Arts, Literature, Humanities and Social Sciences

www.jalhss.com

Volume (74) December 2021

العدد (74) ديسمبر 2021

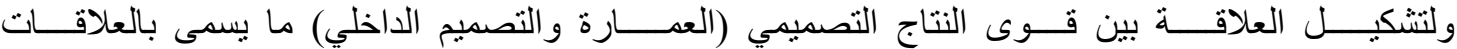

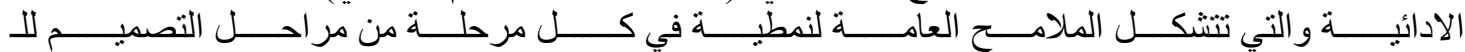

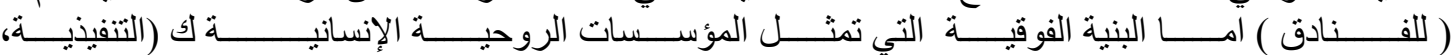

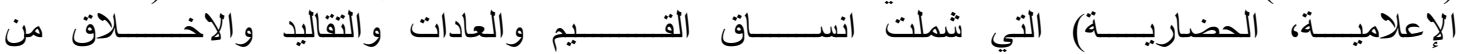

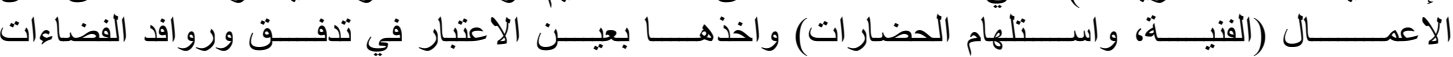

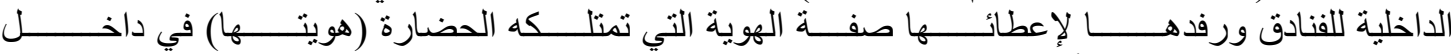

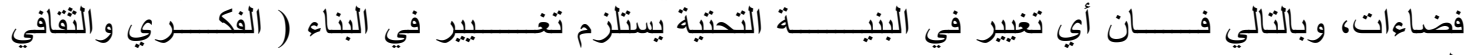
الفوقي ) )

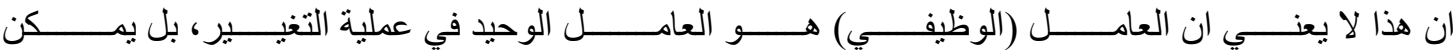

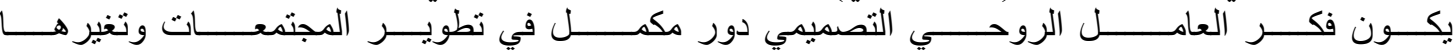

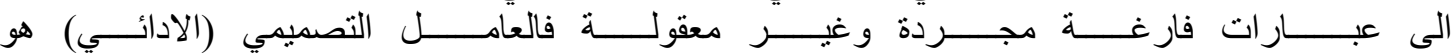

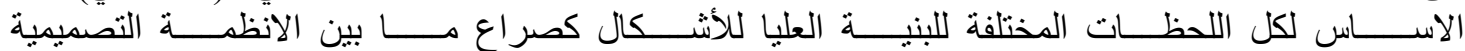

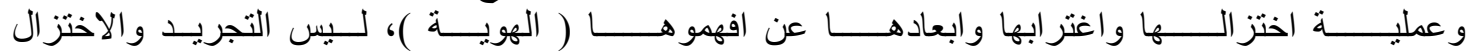

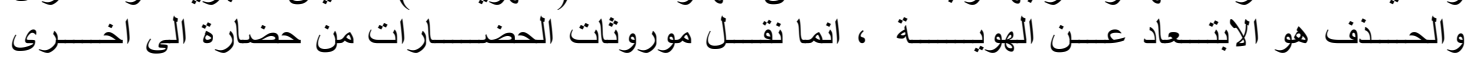

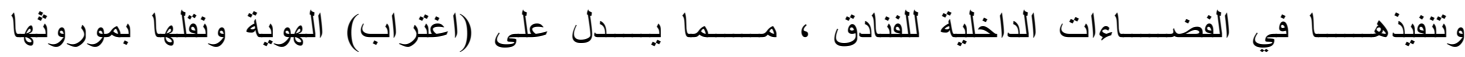

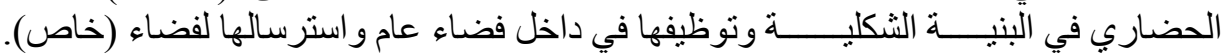

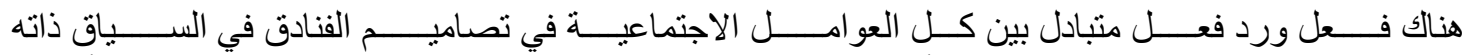

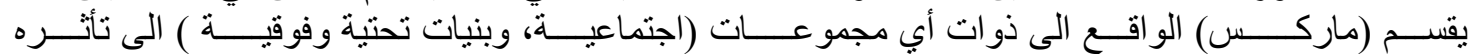

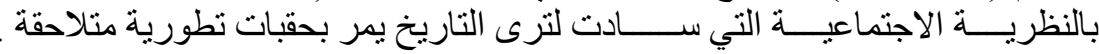

و وان هذا يؤكد ان الطابع الفكري المادي لفلسفة الفضاءات الداخلية للفنادق تشمل التقافات الفكرية فانه لا ينفي عنها

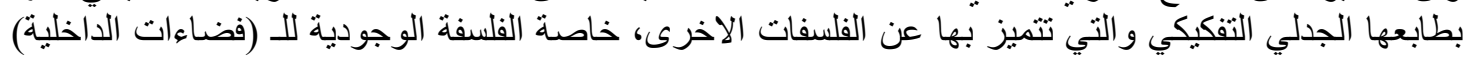

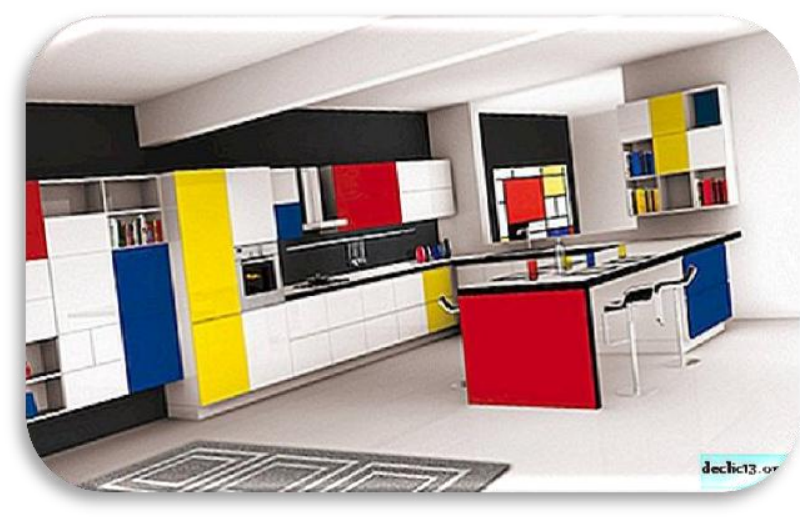

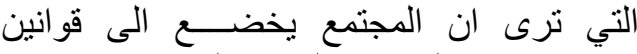

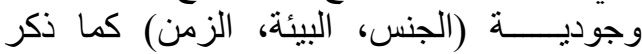
هippolyte Taine)

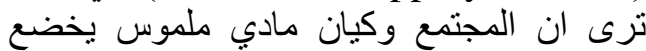

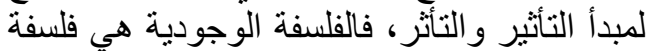

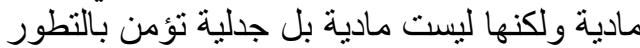

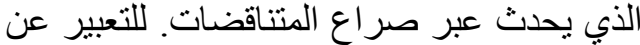

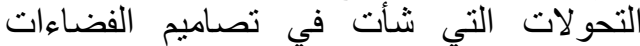

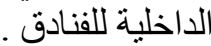

$$
\text { شكل رقم (1-6 ) المصدر الانترنت }
$$

فتصميم الفضاءات الداخلية للفنادق إلى جانب الوظائف هي الخصائص الرئيسية لأسلوب باو هاوس. لا يوجد مكان

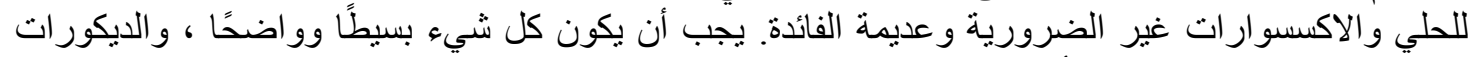
الداخلية مشرقة. يرتبط هذا الأسلوب بالحداثة وقد اكتسب العديد من المؤيدين الذين يفضلون البساطة كما في

الثكل (1) (6-1) 


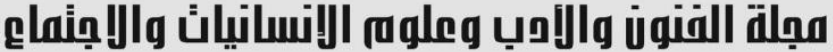

Journal of Arts, Literature, Humanities and Social Sciences www.jalhss.com

Volume (74) December 2021

العدد (74) ديسمبر 2021

\section{¿ÁLHSS}

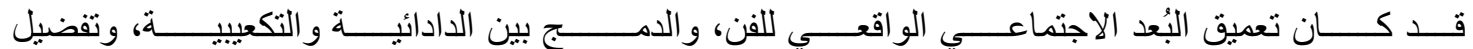

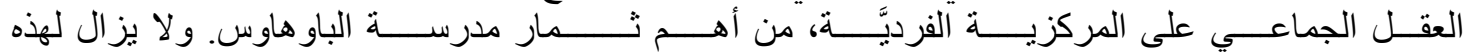

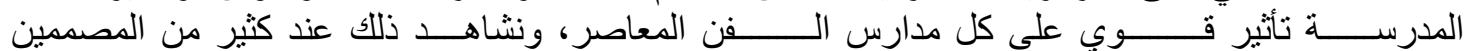
الذين يحاولون إتقان الحِرف أليدويَّة تماثياً مع اتجاه هذه المدرسة.

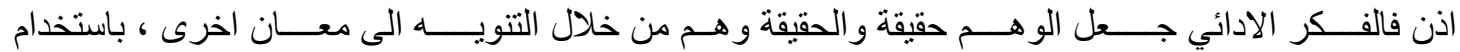

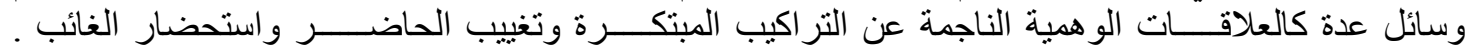

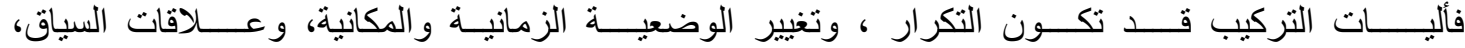

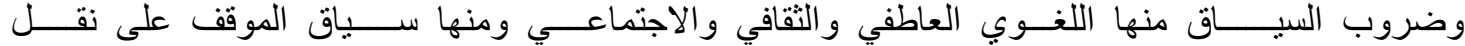
صورته الكامنة بوحدته الثكلية .

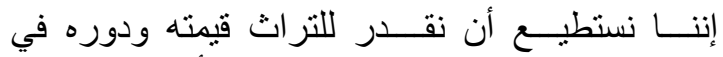

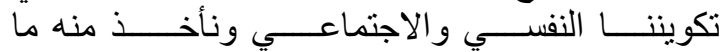

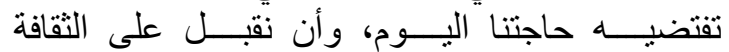

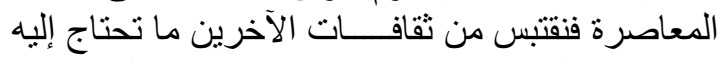

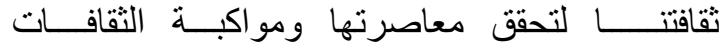

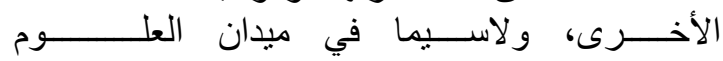

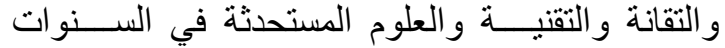

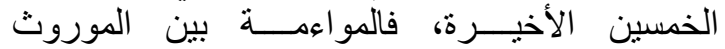

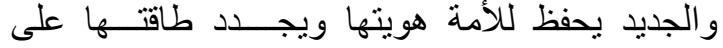

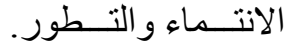

هكذا يوجـــــ على الساحـــة العربية تـــــاران

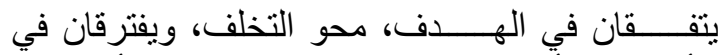
الأسلوب: الأصَالة بالمحافظة على الموروث، أم النبوغ في
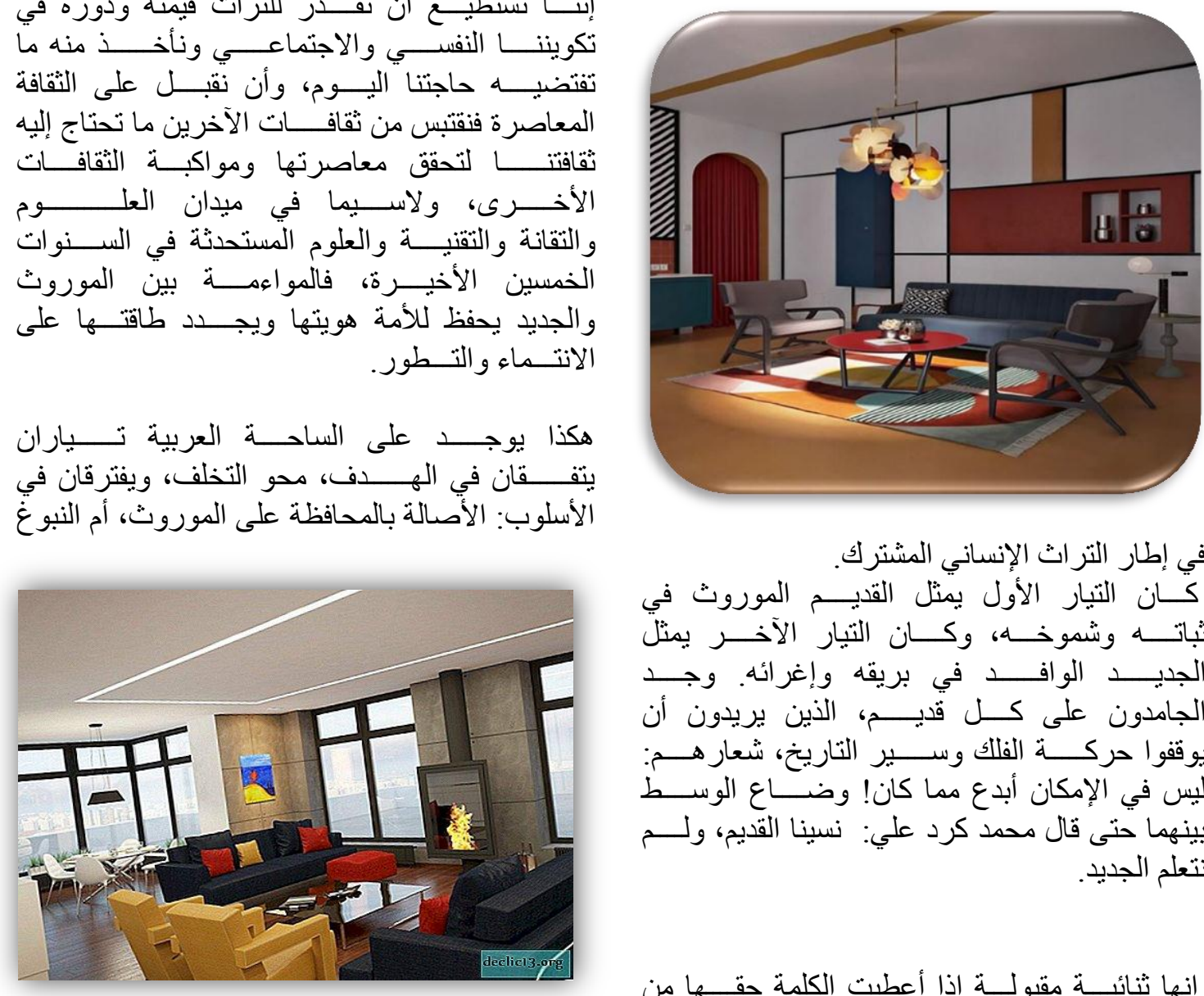

في إطار التراث الإنساني المشترك.

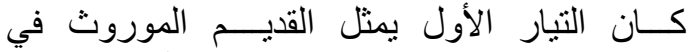

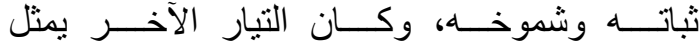

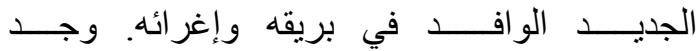

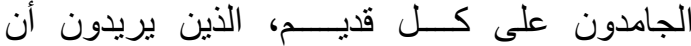

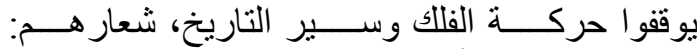

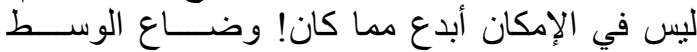

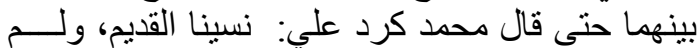

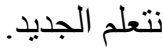

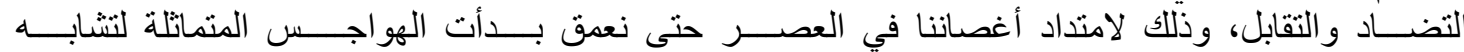

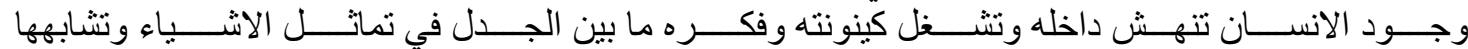

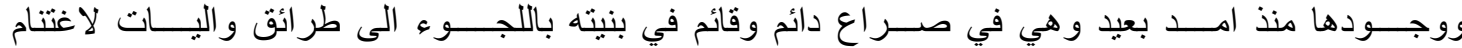

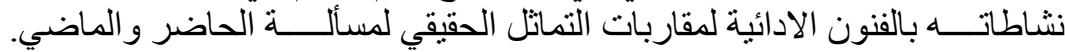




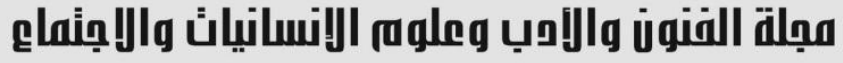

Journal of Arts, Literature, Humanities and Social Sciences www.jalhss.com

Volume (74) December 2021

2021 العدد (74) ديسمبر

يفرق (شوبنهاور) نوعين من تمثنات الأدر الك (الحسي او الحدسي) في اغلب الاحيان يكون الاداء متمثل بالتشابه

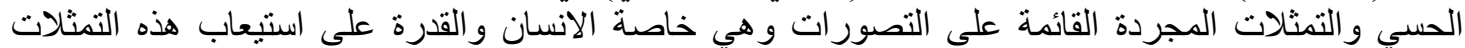
تسمى العقل ان التمثلات التي يعنيها (شوبنهاور) هنا في التمثيلات الحدسية او تمثيلات الادر التئية الك الحسي وملكتها

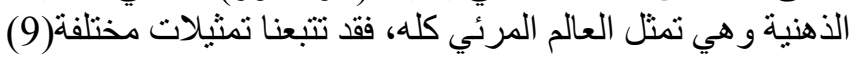

بعد تحليل الانموذج المختارة توصلنا إلى عدد من النتائج ، و هي بما ياتي :-

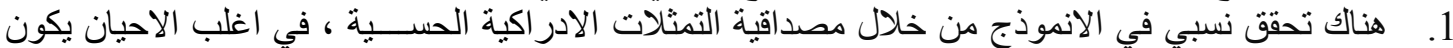

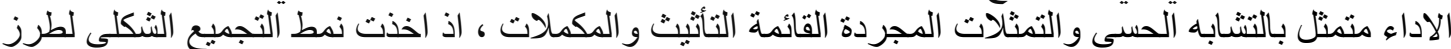

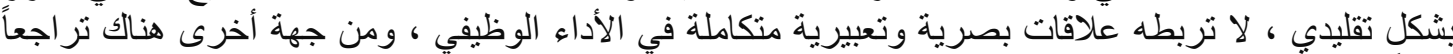

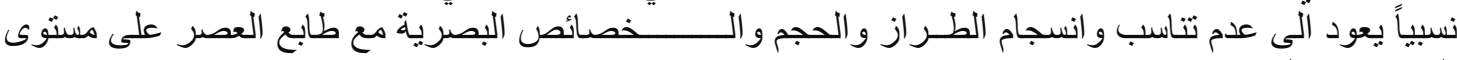

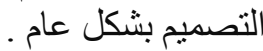

2- حقق شكل الفضاء في الانموذج تماثلات سـاعـدت في تحقيق اسـاليب التعبير لمستوى الحركة من جهة

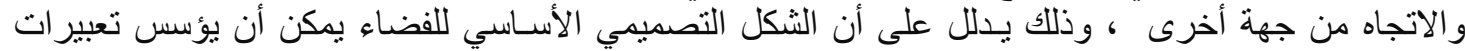

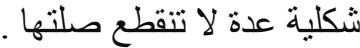

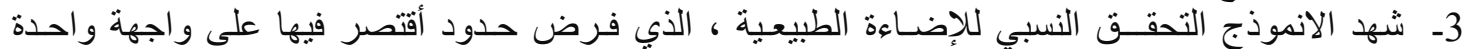
للاتصال مع المحيط حال دون تحقيق اتصال مباثـر مع البيئة المحيطة ، و ادى الىى تحقيق اضـاءة طبيعية مميزه في الفضاء . 4 ـ على الرغم من تحقق التماثلات من خلال الانسجام والتدرج اللوني في الانموذج المنتقاة ، اذ حققت خاصية

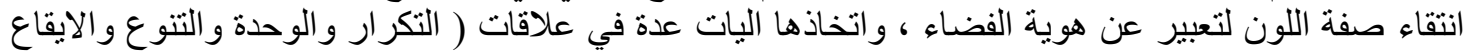
و التباين ..الخ ) ، من جانب اخر كانت هناك تحقق الاظهار بصري وجذب التب الانتباه من خلال تقنيات في مواد

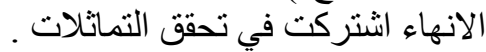

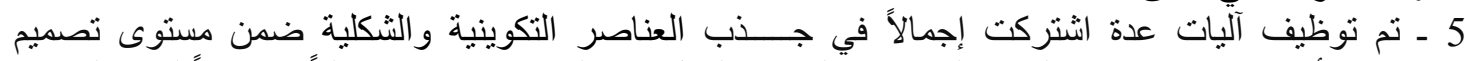

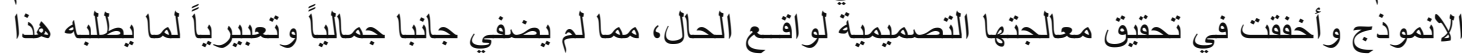
التصميم

\section{الاستنتاحات:}

1. يمكن أن نعد التماثل في التصميم الداخلي دالة حسابية للعلاقة بين مؤسسات الفضاء الذهنية المكونة لعمل

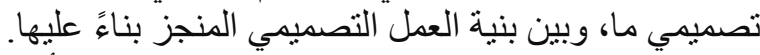
2. في طبيعة تماثل المرتكزات، ما سجل كانقاب أو تحول و اضح بين تصاميم الحداثة وما سبقه في تاريخ

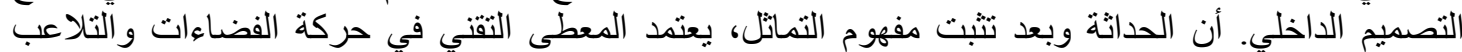
الفيزيائي بخو اصنها في طر ائق الإظهار للفضئ الفاء.

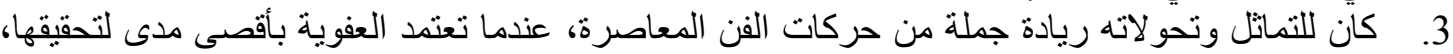

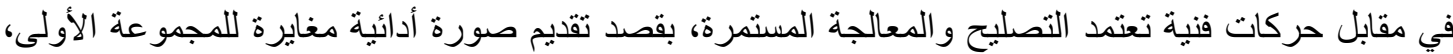
في الغالب تستفيد من معطى علمي وتوظفه أو تحاول مضاهاته بالقدرة اليدوية الإستثنائية.

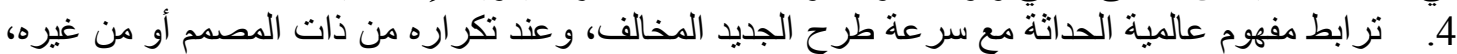

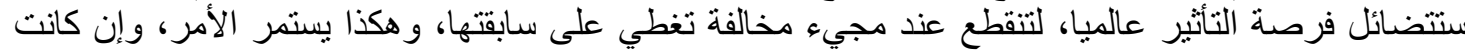

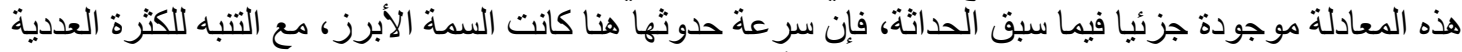

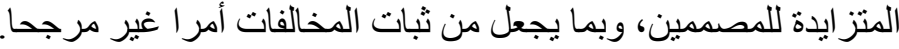
5. سياق التمانل لحركة الحداثة هو سياق تماثل الفضاءات الداخلية، يكون فيه التشابه و التكرار خارج ذللك 


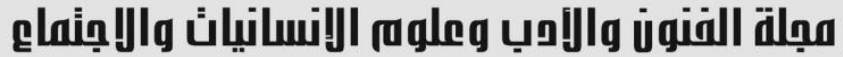

Journal of Arts, Literature, Humanities and Social Sciences

www.jalhss.com

Volume (74) December 2021

العدد (74) ديسمبر 2021

التوصيات

1. يوصسي الباحث بإن يكون تدريس مادة الحداثة بكل مر احله الزمنية، بتقنين يكثف طابع الأنساق الأدائي، و التعريف بالمرتكز ات التي ينطلق عنها التحول التحول من نسق الى آلى آخر.

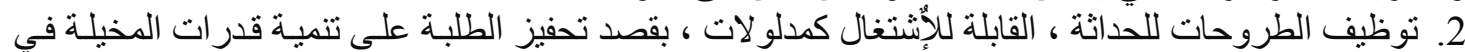
زيادة منافذ الإنتقاء و التناعب الذهني الجديد في ما يختارونه.

\section{الهوامش}

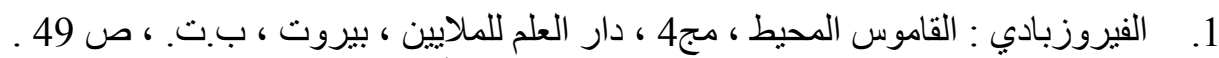

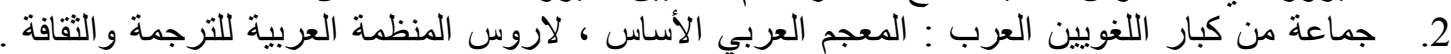

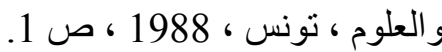

3. J.H.Dunninhg, Globalization, Economic Resbructuring and development uncTDD, un.1994.P.7.

4. تورين ، آلان : نقد الحداثة، ت: أنور مغيت، المجلس الأعلى للثقافة، المطابع الأميرية، القاهرة ، ) . 1992، ص16 5. تورين ، آلان : نقد الحداثة، ت: أنور مغيت، المجلس الأعلى للثقافة، المطابع الأمبرية، القاهرة ، ) 1992،

6. تورين ، آلان: نقد الحداثة ، الحداثة المظفرة ، و لادة الذات ، ت: صباح الجهم ، منشورات وزارة الثقافة ) .

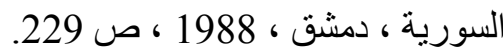
7. و الفنون و الآداب، الكويت، 1998.

8. https://www.farfeshplus.com/Display.asp?catID=141\&mainCatID=139\&sID=153 519 9. تزفيتان تودوروف: المبدأ الحواري - دراسة في فكر ميخائيل باختين، د. منير: فخري صالح، (بغداد: دار الثؤون الثقافية العامة، 1992م) صدون

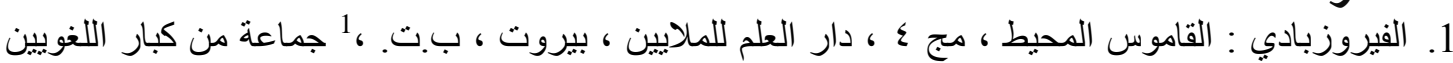

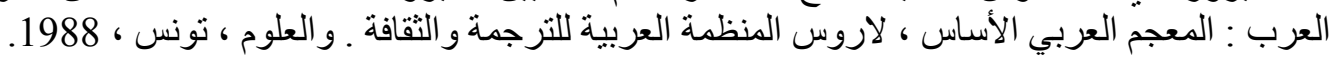

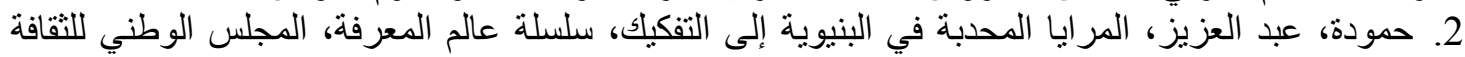

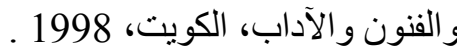
3. تورين ، آلان: نقد الحداثة ، الحداثة المظفرة ، و لادة الذات ، ت: صباح الجهم ، منشورات وزارة الثقافة ) .

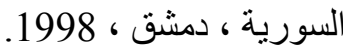
4. تورين ، آلان : نقد الحداثة، ت: أنور مغيت، المجلس الأعلى للثقافة، المطابع الأميرية، القاهرة ، ) ) ، 1992.

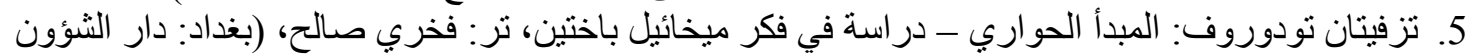

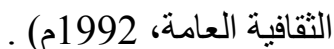
6. بلعقروز ، عبد الرزاق : تحو لات الفكر الفلسفي المعاصر ، اسئلة المفهوم والمعنى و التواصل ، الدار ) العربية

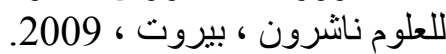
7. J.H.Dunninhg, Globalization, Economic Resbructuring and development uncTDD, un.1994.P.7. 


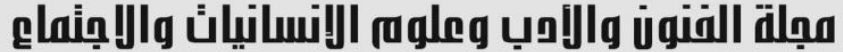 \\ Journal of Arts, Literature, Humanities and Social Sciences www.jalhss.com}

Volume (74) December 2021

العدد (74) ديسمبر 2021

8. https://www.farfeshplus.com/Display.asp?catID=141\&mainCatID=139\&sID=1535 19.

9. Margariti, Kostoula, Christina Boutsouki, Leonidas Hatzithomas, A Typology of 11-Minimalism in Advertising, Research VIII- European Advertising Academy, 2017. a. Moore , Rowan , They came in style , True_Design , issue /summer 17, Switzerland, 2017.

10. Padovan, Richard, Le Corbusier- Mies and De Stijl, Simultaneously published in the USA and Canada by Routledge Madison Ave, New York ,2010 .

11. Tempel ,Benno ‘Hans Janssen,Pieter Tjabbes -DE STIJL E O movimento mondrlan , centro cultural banco do Brasil, Rio de Janeiro, 2017 .

12. https://www.theartstory.org/movement/de-stijl/history-and-concepts/

13. https://ar.wikipedia.org/wiki/

14. https://press.rado.com/sites/default/files.

15. https://onartandaesthetics.com/2016/03/21/de-stijl/ 16 